\title{
Multifocal gastric gastrointestinal stromal tumors (GISTs) with lymph node metastases in children and young adults: A comparative clinical and histomorphological study of three cases including a new case of Carney triad
}

Claudia Otto ${ }^{1 *}$, Abbas Agaimy ${ }^{2}$, Alexander Braun ${ }^{1}$, Jochen Rädecke ${ }^{5}$, Jens Hoeppner ${ }^{5}$, Gerald Illerhaus ${ }^{4}$, Martin Werner', Udo Kontny ${ }^{3}$ and Florian Haller ${ }^{1}$

\begin{abstract}
Background: Gastrointestinal stromal tumors (GISTs) are the most frequent mesenchymal tumors of the gastrointestinal tract usually occurring in the $6^{\text {th }}$ to $7^{\text {th }}$ decade of life, while their occurrence in children is rare $(1-2 \%)$.

Carney triad (CT), a non-hereditary association of gastric GIST with pulmonary chondroma and/or extraadrenal paraganglioma, is an even much rarer disease (to date 120 cases reported worldwide) usually affecting young adult females. Pediatric GISTs differ from CT-associated GISTs solely by the absence of other components of the triad and are completely different from sporadic GISTs of the adult. Both, pediatric and CT-GISTs, metastasize frequently to regional lymph nodes (29\%) and are usually wild type (WT) for common KIT-/PDGFRA mutations.
\end{abstract}

Case presentation and results: We compare one new CT GIST with two pediatric/young adult multifocal gastric GISTs presenting with lymph node metastases. We put special focus on histomorphological growth pattern in the primary tumors and in the metastases.

The two cases of pediatric/young adult GIST without the other components of CT showed all the features of the triad: female gender, young age, multifocal antral-based gastric GIST with biphasic histological growth pattern, lymph node metastases, hypercellularity and WT status for common KIT-, PDGFRA- and B-RAF mutations.

Discussion and conclusion: Pediatric/CT-associated GISTs and sporadic GISTs of the adults differ significantly from each other with regard to patients' age, gender, tumor localisation, histomorphological growth pattern, mutational status and risk for metastasis. Our cases of pediatric/young adult GISTs show all characteristics of CT except for the absence of other components of the triad.

Therefore these GISTs are probably not sporadic, but may represent either early manifestation or forme fruste of the $\mathrm{CT}$. Thus, these patients need to be regularly examined for the development of extraadrenal paraganglioma or pulmonary chondroma.

Virtual Slides: The virtual slide(s) for this article can be found here: http://www.diagnosticpathology.diagnomx.eu/ vs/2074311811556511.

\footnotetext{
* Correspondence: claudia.otto@uniklinik-freiburg.de

1 Institute of Pathology, University Hospital Freiburg, Germany

Full list of author information is available at the end of the article
} 


\section{Background}

Gastrointestinal stromal tumors (GISTs), the most common mesenchymal neoplasms of the gastrointestinal tract (app. 70\%) [1-4] usually affect adults in the $6^{\text {th }}$ and $7^{\text {th }}$ decade of life without any proven gender prevalence [5-8]. However, GISTs represent only a small fraction of all gastrointestinal tumor entities seen in adults $(\leq 2 \%)$ [6-8] and they are rare in childhood and adolescence (1$2 \%$ of all GIST cases) $[5,9,10]$. GISTs in childhood/adolescence can occur as sporadic disease unrelated to a syndrome, present as a familial disorder (e.g. CarneyStratakis syndrome) or be a part of the non-hereditary Carney triad (CT). On the other hand, GISTs in patients affected by neurofibromatosis type 1 usually present at a later age (mean age at presentation $=46$ years) [11]

In 1977 J. Aidan Carney first described the association of gastric epithelioid leiomyosarcoma (later renamed as gastrointestinal stromal tumor) with pulmonary chondroma and functioning extraadrenal paraganglioma of unknown origin, which is today known as CT $[12,13]$.

CT is rare with approximately 120 published cases worldwide to date, usually affects females $(88 \%)$ in their $2^{\text {nd }}$ and $3^{\text {rd }}$ decades $[14,15]$ and often presents with unpredictable outcome [15]. For the diagnosis of CT at least two of the three major components are necessary. Seventy three percent of the patients present with incomplete $\mathrm{CT}$ characterized by manifestation of two components of the disorder $[14,15]$. The most common combination is the association of GIST and pulmonary chondroma (35.6\%) [15]. Recently two other possibly associated tumors were added: leiomyoma of the esophagus and adrenal cortical adenoma $[15,16]$. The gastric GISTs in CT are usually multifocal, antral based and show a wild type (WT) for common mutations in receptor tyrosine kinase gene KIT and for homologue oncogene platelet-derived growth factor receptor $\alpha$ gene (PDGFRA) $[17,18]$ and they present with typical biphasic growth pattern [15]. Approximately $29 \%$ of the patients develop regional lymph node metastases $[15,19,20]$ contrasting with the rarity of lymph node metastasis in sporadic GISTs in adults $(\leq 2 \%)$ [19-22]. Therefore lymph node dissection is not recommended in adult GIST patients $[2,20,23]$. Despite the high tendency for metastasis, especially to regional lymph nodes (29\%) and liver (ca. 25\%), the clinical course of the CT-GISTs is usually indolent with long survivals even with metastatic disease $[15,16]$.

\section{Case presentation and results}

In this study, we describe two new cases of multifocal gastric GIST with lymph node metastases in pediatric/ young adult females and compare the findings with that of a new CT-GIST with special focus on histomorpholo- gical growth pattern, mutational status and the pattern of metastasis.

\section{Case 1}

The first patient, a 15-year-old girl was admitted to the hospital with anaemia caused by upper gastrointestinal bleeding. An antral-based multifocal gastric tumor, suspicious for GIST, was detected in the greater curvature of the stomach. The largest tumor nodule measured 7 $\mathrm{cm}$ in diameter and showed mucosal ulceration. Furthermore multiple liver metastases (maximum diameter: $4 \mathrm{~cm}$ ), were detected preferentially in the left lobe. After confirmation of the diagnosis GIST by open biopsy the patient underwent therapy with imatinib (400 mg once a day $\times 9$ weeks followed by $2 \times 400 \mathrm{mg} / \mathrm{d} \times 2$ weeks). No change in tumor size was observed and the patient underwent gastrectomy and regional lymphadenectomy. The patient has been since then (for now 6 years) on different tyrosine kinase inhibitors including motesanib, sunitinib and nilotinib with only slight progression in the size of liver metastases [24].

The primary tumor showed biphasic histomorphological growth pattern with both, spindled and epithelioid cells. Additionally, hypercellularity as well as plasmacytoid character of the tumor cells was seen. Mitotic count was 5/50 high power fields (HPF; 50 HPFs corresponded to $10 \mathrm{~mm}^{2}$ ). In the liver metastases the tumor cells demonstrated a paraganglioma-like growth pattern with small compact nests, whorls and "Zellballen"-like aggregates of epithelioid tumor cells. Furthermore, histological examination of a $2.5 \times 1.8 \times 1.2 \mathrm{~cm}$ intrathoracic paraaortal nodule thought to represent lymph node metastasis revealed a paraganglioma leading to the diagnosis of incomplete CT with synchronous gastric GIST and extraadrenal paraganglioma.

Immunohistochemistry of the primary tumor showed intensive membranous staining for CD117 and CD34 (figure 1).

Mutational analysis showed a WT for KIT (exons 9, $11,13,17$ ) and PDGFRA (exons 12, 14, 18) as well as for B-RAF exon 15 V600E mutations. However, further examination disclosed a rare PDGFRA exon 10 polymorphism (c. $1432 \mathrm{~T}>\mathrm{C}$; p. S478P) that is present on the DNA level but does not lead to alterations on the protein level.

\section{Case 2}

The second patient, a 13-year-old girl presented with long-lasting anaemia caused by upper gastrointestinal bleeding and worsening general condition. As the initial therapy with ferrous sulphate showed no benefit, ultrasound of the abdomen and magnetic resonance 


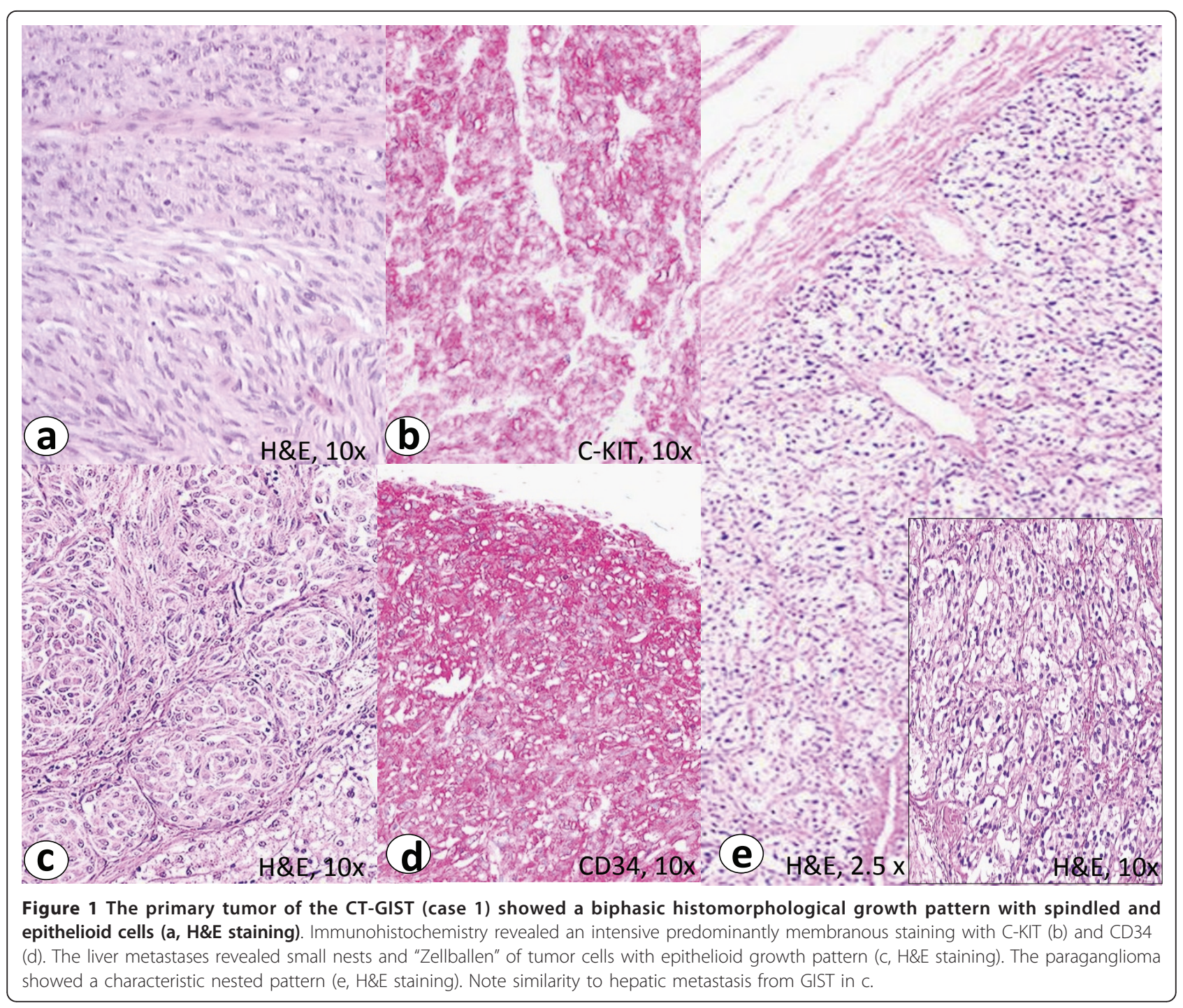

tomography were performed. During these examinations, an $8.1 \times 7.1 \times 5.2 \mathrm{~cm}$ bulky mass attached to the lesser curvature of the stomach as well as multiple hyperdense areas in both lobes of the liver (max. 2.2 $\mathrm{cm}$ ) were discovered. Subsequent gastric endoscopy revealed an exophytic bleeding multilobular gastric tumor with mucosal ulceration. By positron emission tomography the hyperdense areas in the liver were confirmed as metastases of the gastric tumor. The patient then underwent neoadjuvant imatinib therapy followed by $4 / 5$ resection of the stomach with gastrojejunostomy and regional lymphadenectomy of the lesser curvature. Because of the multiplicity of the liver metastases surgeons decided against resection. The patient has been since then for 2 years on imatinib $(400 \mathrm{mg} / \mathrm{d})$ with no major change in size of liver metastases [24].
Histological examination of the gastric specimen revealed an $8 \mathrm{~cm}$ multifocal gastric GIST with mitotic count of 4/50 HPF (intermediate risk after Fletcher et al. and low risk after Miettinen et al.). Furthermore multiple regional lymph node metastases with epithelioid growth pattern were verified. The primary tumor showed biphasic histological growth pattern. Immunohistochemistry showed distinct cytoplasmic and membranous expression of CD117 and CD34 (figure 2).

The tumor was WT for KIT exons 9, 11, 13 and 17, PDGFRA exons 10, 12, 14 and 18 as well as for B-RAF exon 15 mutations.

\section{Case 3}

The third patient, a 40-year-old woman currently presented with liver and lymph node metastases (celiac trunk). 


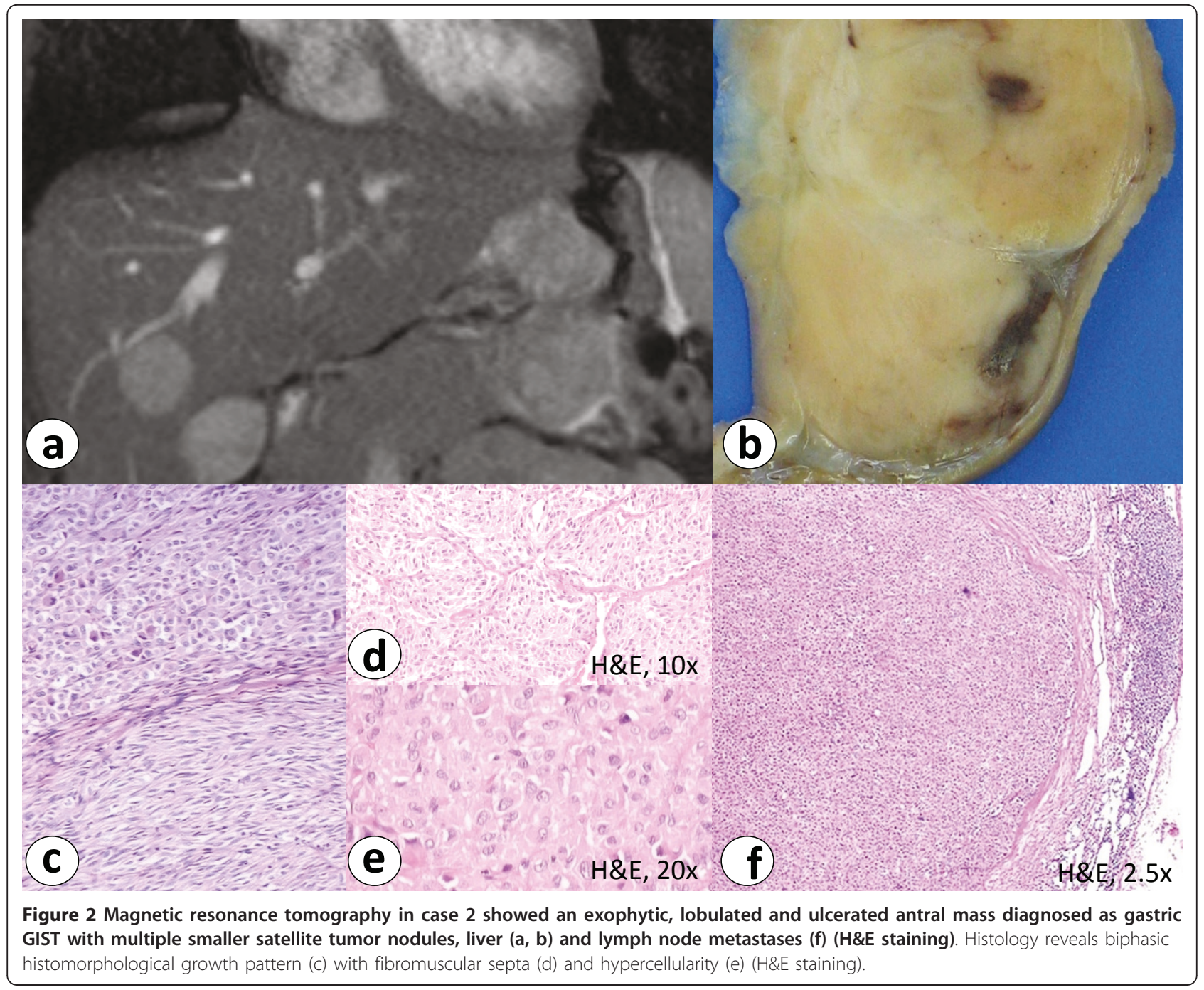

Exploration of her medical history uncovered that the patient underwent partial gastrectomy 17 years ago (23 years old at that time) because of a gastric mesenchymal tumor with hepatic and peritoneal metastasis. At that time the tumor was classified as gastric leiomyosarcoma or malignant stromal tumor of the stomach and the patient was treated with high-dose chemotherapy and autologous stem-cell transplantation [25]. leading to 16 years long term remission. The patient reported nonspecific upper gastrointestinal complaints since the age of 13 .

Unfortunately slides or paraffin blocks of the primary gastric tumor were not available any more for revision, but the histological description found in the medical report was consistent with a GIST. The patients young age, female gender, tumor localisation, mutational status (WT for KIT, PDGFRA and B-RAF mutations), (histo)morphological growth pattern (multilobular gastric tumor, biphasic growth pattern, hypercellularity, plasmacytoid cell morphology), immunohistochemistry findings and the pattern of metastasis (lymph node and liver metastases) are consistent with the previous two cases (figure 3). Up to now there is no evidence for pulmonary chondroma or extraadrenal paraganglioma in this patient and she is well.

\section{Discussion and conclusion}

Sporadic GISTs, usually affecting adults in the $6^{\text {th }}$ and $7^{\text {th }}$ decade of life [5-8], are rare in childhood and adolescence $[5,9,10]$. Currently, the management of sporadic pediatric/young adult GISTs is not standardized, probably due to the relatively low number of reported cases (113 published cases below the age of 21) [26] and lack of complete understanding of the molecular pathogenesis of these usually WT-GISTs.

However, current understanding suggests that sporadic pediatric GISTs represent a tumor entity distinct 


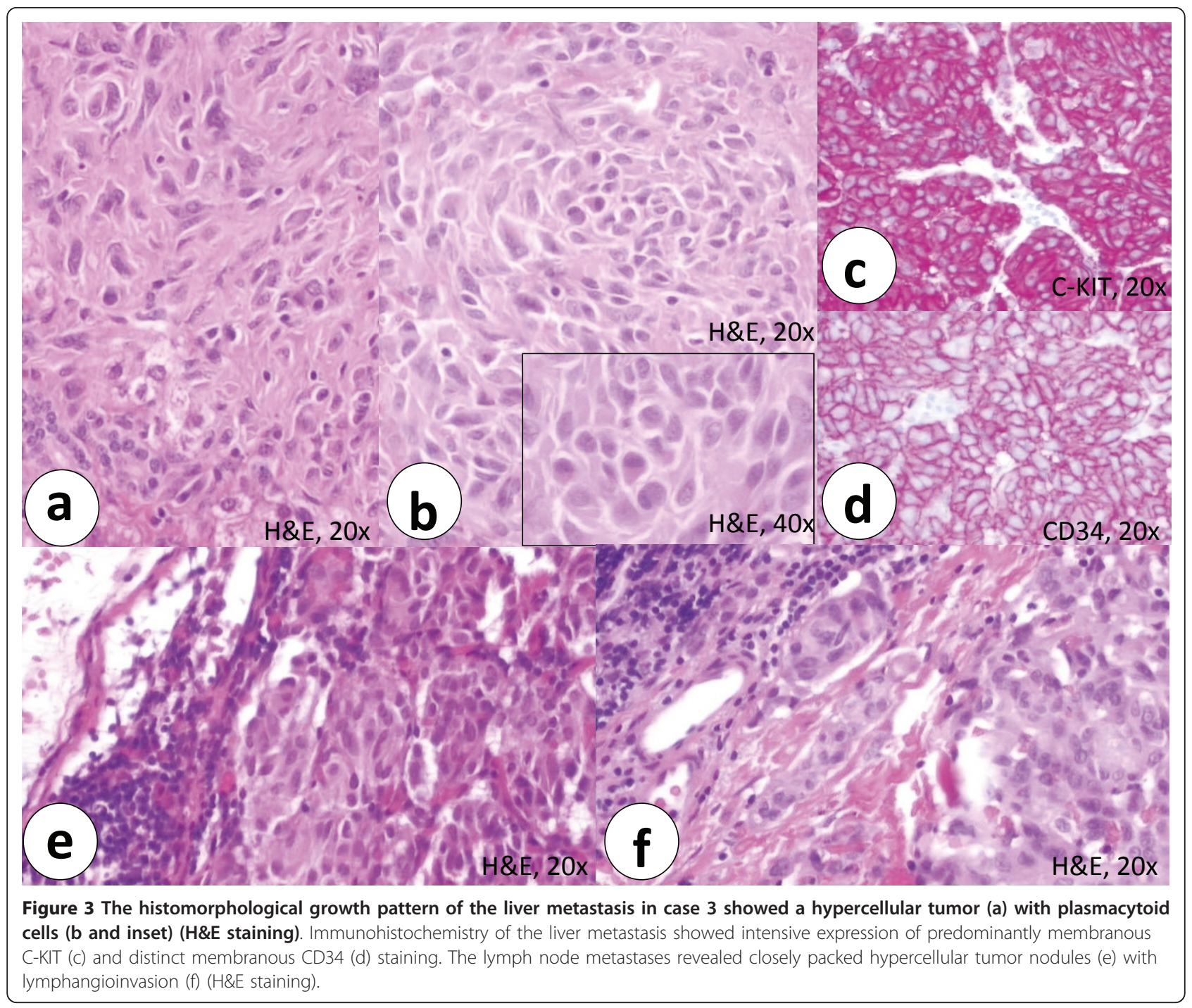

from common GISTs in adults but with striking similarity to CT-GISTs.

WT pediatric GISTs are distinguished from CT-GISTs merely by the absence of other triad components in the latter. In contrast to most of the sporadic GISTs of the adults, both CT-GISTs and pediatric GISTs are WT for common mutations of the receptor tyrosine kinase genes KIT and PDGFRA $[17,18]$. Pediatric and CTGISTs present commonly in childhood and adolescence, show a strong female predilection (88\%), are mostly antral-based, multifocal, show a distinct biphasic histomorphological growth pattern and frequently metastasize to regional lymph nodes, thus strikingly contrasting with common GISTs seen in adults $(\leq 2 \%$ lymph node metastases). The reason for this high rate of lymph node metastasis is not known [20].
Similarly, our two cases of pediatric/young adult GIST without other components of CT (case 2 and 3) showed all the features of the CT-GISTs: young age, female gender, antral-based gastric GIST, multifocal tumor growth, biphasic histological growth pattern, hypercellularity, WT status for common KIT-, PDGFRA- and B-RAF mutations and presence of lymph node metastases (table 1).

Thus, patients diagnosed with WT pediatric GISTs could either represent an early manifestation of CT or a forme fruste of the CT. The time interval from diagnosis of GIST until the appearance of other component/s of the CT averages $\geq 8$ years but may be as long as three decades $[16,27]$. Therefore, these patients should be subjected to regular clinical examination aiming to timely detect possible extraadrenal paraganglioma, pulmonary chondroma and other facultative recently detected 
Table 1 Comparison between Carney triad GIST (case 1), pediatric (case 2) and young adult GIST (case 3)

\begin{tabular}{|c|c|c|c|}
\hline & CT-GIST (case 1) & Pediatric GIST (case 2) & Young adult GIST (case 3) \\
\hline Age at diagnosis (years) & 15 & 13 & 23 \\
\hline Gender & female & female & female \\
\hline Tumor localisation & $\begin{array}{l}\text { stomach, greater } \\
\text { curvature, antrum }\end{array}$ & $\begin{array}{l}\text { stomach, lesser } \\
\text { curvature, antrum }\end{array}$ & stomach, corpus \\
\hline Growth pattern & multinodular & multinodular & multinodular \\
\hline Metastases & $\begin{array}{c}\text { liver } \\
\text { (lymphangioinvasion) }\end{array}$ & $\begin{array}{c}\text { liver } \\
\text { lymph nodes }\end{array}$ & $\begin{array}{c}\text { liver } \\
\text { lymph nodes }\end{array}$ \\
\hline Histomorphology & $\begin{array}{l}\text { biphasic (spindled and } \\
\text { epithelioid), } \\
\text { hypercellular, } \\
\text { plasmacytoid aspect }\end{array}$ & $\begin{array}{l}\text { biphasic (spindled and } \\
\text { epithelioid), } \\
\text { hypercellular, } \\
\text { plasmacytoid aspect }\end{array}$ & $\begin{array}{c}\text { liver metastasis: } \\
\text { hypercellular, } \\
\text { plasmacytoid aspect } \\
\text { lymph node } \\
\text { metastasis: closely } \\
\text { packed hypercellular } \\
\text { tumor nodules with } \\
\text { lymphangioinvasion }\end{array}$ \\
\hline $\begin{array}{l}\text { Immunohisto- } \\
\text { chemistry }\end{array}$ & $\begin{array}{c}\text { C-KIT/CD34 + } \\
\text { (predominantly } \\
\text { membranous) }\end{array}$ & $\begin{array}{c}\text { C-KIT/CD34 + } \\
\text { (predominantly } \\
\text { membranous) }\end{array}$ & $\begin{array}{c}\text { C-KIT/CD34 + } \\
\text { (predominantly } \\
\text { membranous) }\end{array}$ \\
\hline Mutational status & $\begin{array}{c}\text { WT for common C-KIT } \\
\text { (exon 9,11,13,17) and } \\
\text { PDGFRA (exon } \\
\text { 12,14,18) mutations } \\
\text { PDGFRA Exon } 10 \\
\text { polymorphism (c. } 1432 \\
\text { T > C; p. S478P, no } \\
\text { alteration on protein } \\
\text { level) }\end{array}$ & $\begin{array}{l}\text { WT for common C-KIT } \\
\text { (exon 9,11,13,17) and } \\
\text { PDGFRA (exon } \\
12,14,18 \text { ) mutations }\end{array}$ & $\begin{array}{c}\text { WT for common C-KIT } \\
\text { (exon 9,11,13,17) and } \\
\text { PDGFRA (exon } \\
12,14,18 \text { ) mutations }\end{array}$ \\
\hline Associated diseases & $\begin{array}{c}\text { paraaortal } \\
\text { paraganglioma }\end{array}$ & $?$ & $?$ \\
\hline
\end{tabular}

$\mathrm{CT}=$ Carney triad, GIST = gastrointestinal stromal tumor, WT = wild type, $?=$ not to date

components of the triad (leiomyoma of the esophagus and adrenal cortical adenoma).

\section{Author details}

${ }^{1}$ Institute of Pathology, University Hospital Freiburg, Germany. ${ }^{2}$ Institute of Pathology, University Hospital Erlangen, Germany. ${ }^{3}$ Division of Pediatric Hematology and Oncology, Center for Pediatrics and Adolescent Medicine, University Medical Center, Freiburg, Germany. ${ }^{4}$ Department of Gastroenterology, University Hospital Freiburg, Germany. ${ }^{5}$ Department of General Surgery, University Hospital Freiburg, Germany.

\section{Authors' contributions}

All authors read and approved the final manuscript.

\section{Competing interests}

The authors declare that they have no competing interests.

Written informed consent was obtained from the patient/the patients parents for publication of this report and any accompanying images. A copy of the written consent is available for review by the Editor-in-Chief of this journal.

Received: 28 May 2011 Accepted: 10 June 2011 Published: 10 June 2011

\section{References}

1. Miettinen M, Sobin LH, Sarlomo-Rikala M: Immunohistochemical spectrum of GISTs at different sites and their differential diagnosis with a reference to CD117 (KIT). Mod Pathol 2000, 10:1134-1142.

2. Miettinen $M$, Lasota J: Gastrointestinal stromal tumors-definition, clinical, histological, immunohistochemical, and molecular genetic features and differential diagnosis. Virchows Arch 2001, 438(1):1-12.
3. Fletcher CD, Berman JJ, Corless C, Gorstein F, Lasota J, Longley BJ, Miettinen M, O'Leary TJ, Remotti H, Rubin BP, Shmookler B, Sobin LH, Weiss SW: Diagnosis of gastrointestinal stromal tumors: A consensus approach. Hum Pathol 2002, 33:459-465.

4. Yamaguchi U, Hasegawa T, Masuda T, Sekine S, Kawai A, Chuman H, Shimoda T: Differential diagnosis of gastrointestinal stromal tumor and other spindle cell tumors in the gastrointestinal tract based on immunohistochemical analysis. Virchows Arch 2004, 445:142-50.

5. Miettinen $M$, Sobin LH, Lasota J: Gastrointestinal stromal tumors of the stomach. A clinicopathologic, immunohistochemical and molecular genetic study of 1765 cases with long-term follow-up. Am Surg Pathol 2005, 29:52-68.

6. Nilsson B, Bümming P, Meis-Kindblom J, Oden A, Dortok A, Gustavsson B, Sablinska K, Kindblom LG: Gastrointestinal stromal tumors: The incidence, prevalence, clinical course and prognostication in the preimatinib mesylate era. A population-based study in western Sweden. Cancer 2005, 103(4):821-9.

7. Tran T, Davila JA, El-Serag HB: The epidemiology of malignant gastrointestinal stromal tumors: an analysis of 1,458 cases from 1992 to 2000. Am J Gastroenterol 2005, 100(1):162-8.

8. Tryggvason G, Gíslason HG, Magnússon MK, Jónasson JG: Gastrointestinal stromal tumors in Iceland, 1990-2003: the icelandic GIST study, a population-based incidence and pathologic risk stratification study. Int J Cancer 2005, 117(2):289-93.

9. Prakash S, Sarran L, Socci N: Gastrointestinal stromal tumors in children and young adults: a clinicopathologic, molecular, and genomic study of 15 cases and review of the literature. J Pediatr Hematol Oncol 2005, 27:179-187.

10. Agaram NP, Laquaglia MP, Ustun B, Guo T, Wong GC, Socci ND, Maki RG, DeMatteo RP, Besmer P: Molecular characterization of pediatric gastrointestinal stromal tumors. Clin Cancer Res 2008, 14(10):3204-3215. 
11. Wang JH, Lasota J, Miettinen M: Succinate Dehydrogenase Subunit B (SDHB) Is Expressed in Neurofibromatosis 1-Associated Gastrointestinal Stromal Tumors (Gists): Implications for the SDHB Expression Based Classification of Gists. J Cancer 2011, 16(2):90-3.

12. Carney JA, Sheps SG, Go VL, Gordon H: The triad of gastric leiomyosarcoma, functioning extra-adrenal paraganglioma and pulmonary chondroma. N Engl Med 1977, 296:1517-8.

13. Online Mendelian Inheritance in Man, OMIM (TM): Center for Medical Genetics, John Hopkins University, Baltimore, MD and National Center for Biomedical Information, National Library of Medicine, Bethesda, MD. 1999, Updated 11-8-99.

14. Stratakis CA, Carney JA: The triad of paragangliomas, gastric stromal tumours and pulmonary chondromas (Carney triad), and the dyad of paragangliomas and gastric stromal sarcomas (Carney-Stratakis syndrome): molecular genetics and clinical implications. J Intern Med 2009, 266(1):43-52.

15. Zhang L, Smyrk TC, Young WF Jr, Stratakis CA, Carney JA: Gastric stromal tumors in Carney triad are different clinically, pathologically and behaviourally from sporadic gastric gastrointestinal stromal tumors: findings in 104 cases. Am J Surg Pathol 2010, 34:53-64.

16. Carney JA: Gastric stromal sarcoma, pulmonary chondroma and extraadrenal paraganglioma (Carney-Triad): Natural history, adrenocortical component and possible familial occurrence. Mayo Clin Proc 1999, 74:543-52.

17. Agaimy A, Pelz AF, Corless CL, Wünsch PH, Heinrich MC, Hofstaedter F, Dietmaier W, Blanke CD, Wieacker P, Roessner A, Hartmann A, SchneiderStock R: Epithelioid gastric stromal tumours of the antrum in young females with the Carney triad: a report of three new cases with mutational analysis and comparative genomic hybridization. Oncol Rep 2007, 18:9-15.

18. Matyakhina L, Bei TA, McWhinney SR, Pasini B, Cameron S, Gunawan B, Stergiopoulos SG, Boikos S, Muchow M, Dutra A, Pak E, Campo E, Cid MC, Gomez F, Gaillard RC, Assie G, Füzesi L, Baysal BE, Eng C, Carney JA, Stratakis CA: Genetics of Carney triad: recurrent losses at chromosome 1 but lack of germline mutations in genes associated with paragangliomas and gastrointestinal stromal tumors. J Clin Endocrinol Metab 2007, 92:2938-43.

19. Agaimy $A$, Wünsch $P H:$ Lymph node metastasis in gastrointestinal stromal tumours (GIST) occurs preferentially in young patients $\leq 40 \mathrm{yrs}$ : An overview based on our case material and the literature. Langenbecks Arch Surg 2009, 394:375-81.

20. Agaimy A, Carney JA: Lymphatics and D2-40/podoplanin expression in gastrointestinal stromal tumours of the stomach with and without lymph node metastasis: an immunohistochemical study with special reference to the Carney triad. J Clin Pathol 2010, 63(3):229-34.

21. De Matteo RP, Lewis JJ, Leung D, Mudan SS, Woodruff JM, Brennan MF: Two hundred gastrointestinal stromal tumors. Recurrence patterns and prognostic factors for survival. Ann Surg 2000, 231:51-8.

22. Rubin BP: Gastrointestinal stromal tumours: an update. Histopathology 2006, 48(1):83-96.

23. Casali $P G$, Jost $L$, Reichardt $P$, Schlemmer M, Blay JY, ESMO Guidelines Working Group: Gastrointestinal stromal tumors: ESMO clinical recommendations for diagnosis, treatment and follow-up. Ann Oncol 2008, 19(Suppl 2):ii35-8.

24. Benesch M, Leuschner I, Wardelmann E, Thielen M, Schmid I, Kontny U, Ebetsberger G, Frey E, Graf N, Schneider DT, Kremens B, Amann G, Urban C, Schlemmer M, Quehenberger F, Klingebiel T, Dantonello T, Koscielniak E: Gastrointestinal stromal tumours in children and young adults: A clinicopathologic series with long-term follow-up from the database of the Cooperative Weichteilsarkom Studiengruppe (CWS). Eur J Cancer 2011.

25. Fetscher S, Brugger W, Bertz H, Krieger G, Kanz L, Mertelsmann R, Lange W: High-dose chemotherapy with autologous peripheral blood stem cell transplantation for metastatic gastric leiomyosarcoma. Bone Marrow Transplantation 1997, 20:787-788.

26. Benesch $M$, Wardelmann E, Ferrari A, Brennan B, Verschuur A: Gastrointestinal stromal tumors (GIST) in children and adolescents: A comprehensive review of the current literature. Pediatr Blood Cancer 2009, 53(7):1171-9.
27. Carney JA: Carney triad: A syndrome featuring paraganglionic, adrenocortical and possibly other endocrine tumours. J Clin Endocrinol Metab 2009, 94:3656-3662.

doi:10.1186/1746-1596-6-52

Cite this article as: Otto et al:: Multifocal gastric gastrointestinal stromal tumors (GISTs) with lymph node metastases in children and young adults: A comparative clinical and histomorphological study of three cases including a new case of Carney triad. Diagnostic Pathology 2011 6:52.

\section{Submit your next manuscript to BioMed Central and take full advantage of:}

- Convenient online submission

- Thorough peer review

- No space constraints or color figure charges

- Immediate publication on acceptance

- Inclusion in PubMed, CAS, Scopus and Google Scholar

- Research which is freely available for redistribution

Submit your manuscript at www.biomedcentral.com/submit
Biomed Central 